\title{
An Inverted U-Shaped Relationship between Public Debt and Economic Growth under the Golden Rule of Public Finance
}

\author{
Mitsuru Ueshina $^{1 *}$, Tamotsu Nakamura ${ }^{2}$ \\ ${ }^{1}$ Faculty of Economics, Matsuyama University, Ehime, Japan \\ ${ }^{2}$ Graduate School of Economics, Kobe University, Hyogo, Japan \\ Email: *mueshina@g.matsuyama-u.ac.jp
}

How to cite this paper: Ueshina, M. and Nakamura, T. (2019) An Inverted U-Shaped Relationship between Public Debt and Economic Growth under the Golden Rule of Public Finance. Theoretical Economics Letters, 9, 1792-1803.

https://doi.org/10.4236/tel.2019.96114

Received: June 12, 2019

Accepted: August 6, 2019

Published: August 9, 2019

Copyright $\odot 2019$ by author(s) and Scientific Research Publishing Inc. This work is licensed under the Creative Commons Attribution International License (CC BY 4.0).

http://creativecommons.org/licenses/by/4.0/

\section{Open Access}

\begin{abstract}
Empirical evidence shows an inverted U-shaped relationship between public debt-to-GDP ratio and economic growth for many advanced economies. Using a simple endogenous growth model with public debt under the Golden Rule of Public Finance (GRPF), which allows the government to issue bonds only to finance public investment, this paper explains the relationship. Although Greiner [1] explains it in the similar model, he introduces a more restrictive assumption than GRPF that the amount of public investment must be always equal to that of newly issued bonds, i.e., public investment must be financed only by newly issued bonds. This paper shows that the assumption is not needed. In other words, the inverted U-shaped relationship emerges in a more realistic case when public investment is partly financed by other sources than government bonds such as taxes.
\end{abstract}

\section{Keywords}

Inverted U-Shape, Public Debt, Economic Growth, Golden Rule of Public Finance

\section{Introduction}

For many advanced economies such as the United States, Japan, and European countries, the accumulated public debt has been one of the biggest concerns. It not only increases the risk for the fiscal sustainability but also decreases the freedom of fiscal policies. If a high debt-GDP ratio itself has bad impacts on the economy, especially on the growth performance, then the economy has difficulty of getting out of the high debt-GDP ratio trap once it has accumulated a certain 
level of debt. Therefore, the relationship between public debt and economic growth is of crucial importance in exploring the future of the economy.

Quite naturally, therefore, many theoretical and empirical studies have analyzed the economic effects of public debt and fiscal deficits on growth performance. Reinhart and Rogoff [2] examine the relationship between public debt and economic growth for many advanced economies since the nineteenth century to confirm the conventional wisdom that very high public debt has bad influences on economic activities. In concrete, the economic growth rates during high public debt periods, which are defined as those with over 90 percent debt-GDP ratios, are 1.2 percent lower than normal periods on average. Also, they introduce 26 episodes of high public debt periods, 20 episodes of which are over a decade-long.

Checherita-Westphal and Rother [3] investigate the effects of public debt on per-capita GDP growth for 12 Euro area economies. As a result, it is shown that there exists a non-linear relationship between debt-GDP ratio and per-capita GDP growth. To be more concrete, if debt-GDP ratio is below a certain threshold, then an increase in public debt enhances economic growth. If, conversely, it is above the threshold, then an increase in public debt lowers economic growth. They show that the threshold of debt-GDP ratio is around $90-100$ percent, which is close to the ratio estimated by Reinhart and Rogoff [2] and Reinhart et al. [4]. Baum et al. [5] also analyze the relationship between debt-GDP ratio and economic growth for the Euro area. They find that the effect of public debt on GDP is positive in the short run until the ratio reaches a certain level of debt-GDP ratio. After reaching a 95 percent level, the effect of public debt on growth becomes negative. Based on these findings, Baum et al. [5] conclude that a bond-financed fiscal stimulus is effective only when the debt-GDP ratio is low.

In sharp contrast to the aforementioned empirical results, many of theoretical studies at an early stage suggest that relationship between public debt and economic growth is monotonically negative. For example, Saint-Paul [6] investigates a continuous-time overlapping generations model a la Blanchard [7] with endogenous growth to find that an increase in debt-GDP reduces economic growth. Bräuninger [8] also makes an important contribution to the relationship between the ratio of fiscal deficit to GDP and economic growth. Using an overlapping generations framework, he first shows that, if the deficit ratio is below some critical level, then there exist two steady states, and then proves that an increase in deficit-GDP ratio renders economic growth. The reason for the monotonic negative relationship between public debt and economic growth is that those models assume that government expenditures have no effect on production. In reality, however, government expenditures include those having positive impacts on the productivity of the economy as a whole such as such public service and public investment. It, in fact, is evident from Barro [9] and Futagami et al. [10] among others that public investment is commonly assumed to have positive 
growth effects in the endogenous growth literature ${ }^{1}$.

In analyzing the long-run relationship between public debt and economic growth, the fiscal sustainability must be considered. One of the most plausible ways to ensure the sustainability is the introduction of the Golden Rule of Public Finance (GRPF), under which public bonds can be exclusively used for the productive purposes, i.e., public investment. The amount of newly issued bonds cannot therefore exceed that of public investment. Checherita-Westphal et al. [11] investigate an endogenous growth model with public debt and productive public capital under GRPF to derive the growth maximizing debt-GDP ratio in the long-run. They not only extend the theoretical analysis but also give the robust estimates of the growth-maximizing debt-to-GDP ratios for the OECD, EU and euro area countries ${ }^{2}$.

Greiner [1] extends their theoretical model to examine the conditions under which an inverted U-shaped relationship emerges. As a result, it is shown that if the amount of public investment is exactly equal to that of newly issued bonds, then the relationship emerges. This is intuitively consistent with the result of Futagami et al. [10] that the relationship between public capital-GDP ratio and economic growth is inverted U-shaped because public capital-to-GDP ratio increases with debt-GDP when public investment is equal to newly issued bonds in Greiner's model. In reality, however, a part of public investment is financed by other sources than government bonds such as taxes. In other words, the condition that public investment is financed only by newly issued bonds is not only restrictive but unrealistic.

In this paper, therefore, we reexamine the conditions under which an inverted U-shaped relationship between debt-GDP ratio and economic growth emerges in an endogenous growth model. To be more concrete, we consider the more realistic case in which public investment is financed not only by newly issued bonds but also by other sources, i.e., a part of public investment is financed by taxes. As a result, it is shown that the assumption employed in Greiner [1] is not needed to derive the inverted $\mathrm{U}$-shaped relationship. In other words, the relationship emerges even when some portion of public investment is financed by public bonds, while the remaining portion by taxes.

The rest of paper is organized as follows. Section 2 sets up the endogenous growth model with public debt and productive public capital. Section 3 analyzes the model to derive the main propositions. Section 4 shows findings in the analysis. Section 5 concludes the paper.

\section{The Model}

Since the framework of the model is basically the same as Greiner [1], the presentation will be concise. We consider an endogenously growing competitive ${ }^{1}$ Since, however, the government budget is assumed to be balanced in Barro [9] and Futagami et al. [10], no public debt exist, and hence the effect has not been explored.

${ }^{2}$ Ghosh and Mourmouras [12] point out that budgetary regimes such as GRPF are important in considering the optimal fiscal policy using a similar model to ours. 
economy consisting of three agents: households, firms and the government. Firms produce final output, which can be used both for consumption and investment. Investment in turn becomes productive private or public capital. Greiner [1] introduces public debt into Futagami et al. [10], in which they analyze an endogenous growth model with public capital assuming the balanced budget rule. In contrast, following Greiner [1], we allow the government to issue bonds that are used only for public investment. The same setting is also employed in Bokan et al. [13], Ueshina [14], and Kamiguchi and Tamai [15].

\subsection{Households}

The number of households is constant over time and normalized to unity. Each household maximizes the discounted sum of instantaneous utilities ${ }^{3}$ :

$$
\max _{c(t)} \int_{0}^{\infty} \mathrm{e}^{-\rho t} \ln C(t) \mathrm{d} t
$$

subject to the following flow budget constraint:

$$
\dot{K}(t)+\dot{B}(t)=r(t) B(t)+(1-\tau) Y(t)-C(t),
$$

where $\rho$ is the time preference rate, $C(t)$ is consumption, $K(t)$ is private capital, $B(t)$ is public debt, $r(t)$ is the interest rate, $\tau \in(0,1)$ is a constant tax rate on output, and $Y(t)$ is output ${ }^{4}$. Since we assume that the population is constant at unity through time, each variable represents its per-capita value.

\subsection{Firms}

The production function is given by

$$
Y(t)=A K(t)^{1-\alpha} G(t)^{\alpha},
$$

where $G(t)$ is public capital, $A$ is a technology parameter, and $\alpha \in(0,1)$ is the elasticity of output with respect to public capital. In equilibrium, the interest rate is equal to the marginal product of private capital net of taxes:

$$
r(t)=(1-\tau)(1-\alpha) A K(t)^{-\alpha} G(t)^{\alpha} .
$$

\subsection{Government}

The government levies taxes on output and issues bonds in order to finance the expenditures. To simply the analysis, suppose that public capital does not depreciate. Then the government flow budget constraint is

$$
\dot{B}(t)=r(t) B(t)-\tau Y(t)+\dot{G}(t) .
$$

The government must also satisfy the following intertemporal budget constraint:

$$
\lim \mathrm{e}^{-r t} B(t)=0 \text {. }
$$

Let us introduce the following fiscal rule, i.e., the rule on the bond issue:

${ }^{3}$ Although we assume a logarithmic utility function following Greiner [1], our results hold even if we assume that the value of elasticity of substitution isn't limited to one.

${ }^{4}$ Introducing capital taxation, i.e., taxes on capital income $r(t) B(t)$, does not change the results. 


$$
\dot{B}(t)=\psi \dot{G}(t) \text { with } \psi \in(0,1) .
$$

Equation (6) means that the amount of newly issued bonds $\dot{B}(t)$ cannot exceed that of public investment $\dot{G}(t)$. Putting it differently, the government can issue bonds only to finance public investment, i.e., $\dot{B}(t)=0$ when $\dot{G}(t)=0$. This rule, which restricts the bond issue to productive purposes of public investment, is referred to as the "Golden Rule of Public Finance (GRPF)".

For the government to follow GRPF, $\psi$ must be less than or equal to one. However, it needs not to be necessarily equal to one. To simplify the analysis, Greiner [1] assumes that $\psi$ is equal to one and explains an inverted U-shaped relationship between debt-GDP ratio and economic growth. In what follows, in contrast, we assume that $0<\psi<1$. Hence, we consider the model with a more general GRPF than in Greiner [1].

\section{Equilibrium Analysis}

\subsection{The Existence of Steady State}

Solving the optimization of the household, the consumption growth is given by the following equation:

$$
g_{C}(t)=\frac{\dot{C}(t)}{C(t)}=-\rho+(1-\tau)(1-\alpha) A\left(\frac{G(t)}{K(t)}\right)^{\alpha} .
$$

Combining the household's budget constraint (2) and government's budget constraint (5), the growth of private capital becomes

$$
g_{K}(t)=\frac{\dot{K}(t)}{K(t)}=A\left(\frac{G(t)}{K(t)}\right)^{\alpha}-\frac{C(t)}{K(t)}-\left(\frac{\dot{G}(t)}{G(t)}\right)\left(\frac{G(t)}{K(t)}\right) .
$$

In use of equation (5) and (6), we obtain the growth of public debt and public capital as follows ${ }^{5}$ :

$$
\begin{gathered}
g_{B}(t)=\frac{\dot{B}(t)}{B(t)}=\psi\left(\frac{G(t)}{K(t)}\right)\left(\frac{K(t)}{B(t)}\right)\left(\frac{\dot{G}(t)}{G(t)}\right) \\
g_{G}(t)=\frac{\dot{G}(t)}{G(t)}=(1-\psi)^{-1}\left(\tau A\left(\frac{G(t)}{K(t)}\right)^{\alpha-1}-(1-\tau)(1-\alpha) A\left(\frac{G(t)}{K(t)}\right)^{\alpha-1} \cdot \frac{B(t)}{K(t)}\right)
\end{gathered}
$$

Turning to the steady state of the economy in which all variables grow at the same constant rate $g^{*}$, and hence the ratios of two variables are constant through time, the Equations (7) to (10) become as follows:

$$
\begin{gathered}
g_{C}=\frac{\dot{C}}{C}=g^{*}=-\rho+(1-\tau)(1-\alpha) A z^{* \alpha}, \\
g_{K}=\frac{\dot{K}}{K}=g^{*}=A z^{* \alpha}-c^{*}-g^{*} z^{*},
\end{gathered}
$$

${ }^{5}$ We should note that Equation (10) cannot be derived in the case of $\psi=1$, which is assumed in Greiner [1]. Substituting it for Equation (10), the rate of growth of public capital is indeterminate because both the numerator and denominator become zero simultaneously. 


$$
\begin{gathered}
g_{B}=\frac{\dot{B}}{B}=g^{*}=\psi \frac{z^{*}}{b^{*}} g^{*}, \\
g_{G}=\frac{\dot{G}}{G}=g^{*}=(1-\psi)^{-1}\left(\tau-(1-\tau)(1-\alpha) b^{*}\right) A z^{* \alpha-1},
\end{gathered}
$$

where each lowercase letter represents the per-capitalvalue of the corresponding uppercase letter, i.e., $c \equiv C / K, z \equiv G / K$, and $b \equiv B / K$.

Finally, the following condition must be imposed for the non-degenerate steady state ${ }^{6}$ :

$$
\psi \leq \tau[(1-\alpha)(1-\tau)]^{\frac{1-\alpha}{\alpha}}\left(\frac{A}{\rho}\right)^{\frac{1}{\alpha}} .
$$

Equation (13) implies

$$
\psi z^{*} / b^{*}=1 \text { or } b^{*}=\psi z^{*} .
$$

Substitution of Equation (15) into Equation (14) gives

$$
g^{*}=(1-\psi)^{-1}\left(\tau-(1-\tau)(1-\alpha) \psi z^{*}\right) A z^{* \alpha-1} .
$$

From Equations (11) and (16), we have

$$
-\rho+(1-\tau)(1-\alpha) A z^{* \alpha}=(1-\psi)^{-1}\left(\tau-(1-\tau)(1-\alpha) \psi z^{*}\right) A z^{* \alpha-1} .
$$

This equation can be rewritten as

$$
(\mathrm{LHS}=)(1-\tau)(1-\alpha) A z^{* \alpha}=\tau A z^{* \alpha-1}+(1-\psi) \rho(=\mathrm{RHS}) .
$$

The LHS and RHS of Equation (17) can be depicted as in Figure 1 because each of them is a function of $z$. Since the LHS curve is upward sloping through the origin, while the RHS is downward sloping as Figure 1 shows, there exists a unique steady state.

\subsection{The Effects of Tax Rate}

Taking advantage of Figure 1, let us examine the effects of the tax rate $\tau$ on the steady state. An increase in $\tau$ shifts down the LHS curve, while it shifts up the RHS curve. The solid lines in Figure 1 represent the curves after an increase in tax rate. As a result, the ratio of public capital to private capital in the steady state $z^{*} \equiv G / K$ surely increases. The same result can of course be obtained by applying the implicit-function theorem to Equation (17):

$$
\frac{\mathrm{d} z^{*}}{\mathrm{~d} \tau}=\frac{\left[(1-\alpha) z^{*}+1\right] z^{*}}{(1-\alpha)\left[(1-\tau) \alpha z^{*}+\tau\right]}>0 .
$$

Differentiating the growth rate in Equation (11) with respect to $\tau$, we obtain:

$$
\frac{\mathrm{d} g^{*}}{\mathrm{~d} \tau}=-(1-\alpha) A z^{* \alpha}+(1-\tau)(1-\alpha) A z^{* \alpha-1} \frac{\mathrm{d} z^{*}}{\mathrm{~d} \tau} .
$$

Substitution of Equation (18) into the above gives,

${ }^{6}$ See Appendix for the derivation of the condition. 


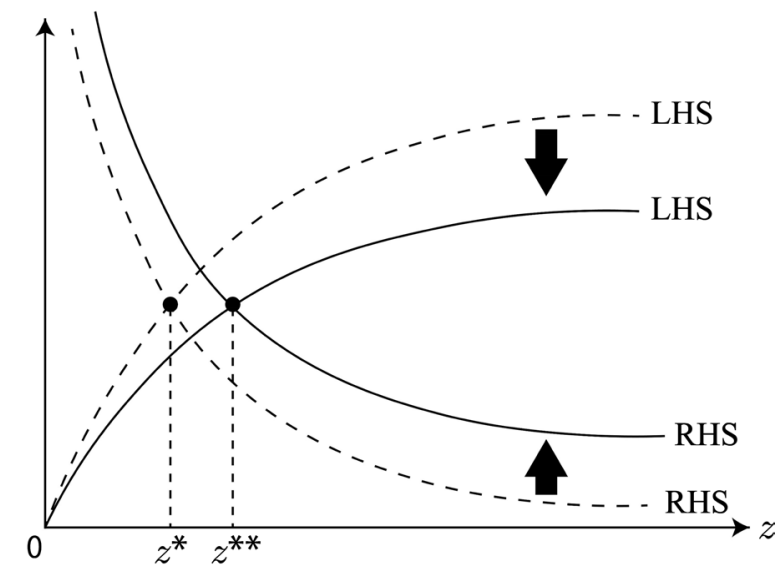

Figure 1. Existence of unique steady state and effects of tax rate.

$$
\frac{\mathrm{d} g^{*}}{\mathrm{~d} \tau}=\frac{(\alpha-\tau) A z^{* \alpha}}{(1-\tau) \alpha z^{*}+\tau} .
$$

Hence, the relationship between the tax rate and growth rate is given by:

$$
\operatorname{sign}\left(\frac{\mathrm{d} g^{*}}{\mathrm{~d} \tau}\right)=\operatorname{sign}(\alpha-\tau) .
$$

Equation (19) shows that the growth maximizing tax rate is equal to the elasticity of output with respect to public capital $\alpha$. Also, the long-run growth rate $g^{*}$ increases with tax rate $\tau$ when $\tau$ is below $\alpha$, and vice versa. These observations lead to the following proposition.

\section{Proposition 1}

Under the Golden Rule of Public Finance there exists a unique tax rate that maximizes the long-run growth rate. In other words, the relationship between tax rate and growth is inverted U-shaped in the steady state.

The above proposition is the same as in Barro [9] and Futagami et al. [10]. It, however, should be noted that no public debt exists in their models because the government budget is assumed to be balanced. Since the proposition makes it clear that the same result holds under the existence of public debt, it can be considered as a generalization of their distinguished contribution ${ }^{7}$.

\subsection{The Inverted U-Shaped Relationship}

Taking the conditions held in the steady state into account, we can rewrite the production function (3) as follows:

$$
d^{*}=\left(\psi^{\alpha} / A\right) b^{* 1-\alpha},
$$

where $d^{*}=(B / Y)^{*}$ is the debt-GDP ratio in the steady state. Using Equation (15), the above equation can be further rewritten as:

$$
d^{*}=(\psi / A) z^{* 1-\alpha} .
$$

${ }^{7}$ The result is also consistent with the empirical evidence shown by Huňady and Orviská [16] that the effect of corporate tax on economic growth is inverted U-shaped in member states of the European Union. For the growth maximizing tax rates, see also Huňady and Orviská [16]. 
As equation (18) shows, $z^{*}$ increases with $\tau$. In other words, other things being equal, $z^{*}$ moves in the same direction as $\tau$. Since, as Proposition 1 states, the relationship between $\tau$ and $g^{*}$ is inverted U-shaped, the relationship between $z^{*}$ and $g^{*}$ is also inverted U-shaped. Now we come to the following proposition.

\section{Proposition 2}

Under the Golden Rule of Public Finance the relationship between debt-GDP ratio and the long-run growth is inverted U-shaped regardless of the share of public investment financed by government bonds.

\section{Findings}

The analysis of Subsection 3.1 - 3.2 implies that the relationship between tax rate and growth is inverted U-shaped in the steady state. From Subsection 3.3, which shows debt-GDP ratio increases with tax rate, we derive the relationship between debt-GDP ratio and growth is inverted U-shaped.

It should be noted that Proposition 1 holds regardless of the value of $\psi$, although, as Appendix shows, it surely affects the long-run growth. So does Proposition 2. Greiner [1] derives the inverted U-shaped relationship under the assumption of $\psi=1$. The proposition points out that the restrictive assumption is not needed. In other words, the GRPF suffices to explain the relationship.

One of the key mechanisms to derive the inverted $\mathrm{U}$-shaped relationship is that the long-run debt-GDP ratio $d^{*}$ increases with tax rate $\tau$. This seems counterintuitive because a tax rate hike increases the government revenues and hence seems to reduce the amount of newly issued bonds. Looking only at the instantaneous budget constraint, it is the fact in the short-run that an increase in the government revenues reduces newly issued bonds. The government, however, follows the intertemporal or long-run budget constraint. A tax rate hike implies increases not only in current revenues bud also in the future revenues. In other words, the government can increase public debt because it will be able to bear the increased burden thanks to the tax revenue increases in the future. As a result, the debt-GDP ratio in the steady state increases with tax rate under $\mathrm{GRPF}^{8}$.

\section{Concluding Remarks}

This paper investigates an endogenous growth model with public debt as well as with private and public capital to analyse the long-run relationship between debt-to-GDP ratio and economic growth. As a result, it is shown that the inverted U-shaped relationship emerges under the Golden Rule of Public Finance (GRPF), which allows the government to issue bonds only to finance public investment, i.e., the amount of newly issued bonds must be less than or equal to the amount of public investment.

The inverted U-shaped relationship, which is consistent with empirical evi${ }^{8}$ Since it also true when $\psi=1$, Greiner [1] derives the same result. 
dence, has already been explained by Greiner [1] in the same framework as in this paper. He, however, imposes an assumption to derive the result that the amount of newly issued bonds is always equal to the amount of public investment. The assumption is restrictive in that it is an extreme case of GRPF. In contrast, this paper makes it clear that the relationship emerges without the assumption or under less-restrictive conditions. In other words, GRPF is sufficient to explain the relationship in Greiner's framework.

GRPF itself might be a restrict assumption because the government issues new bonds to finance other expenditures than public investment such as social security expenses. In reality, public debt has been increasing mainly due to an increase in social security expenses caused by low birth rates and aging in many advanced economies. It deserves future research to analyse the relationship taking the important aspects into account.

\section{Acknowledgements}

The authors would like to thank Kenichiro Ikeshita, Toshiyuki Kawai, Takeshi Koba, and participants at the 2015 Fall Meeting of the Japanese Association of Applied Economics, and an anonymous referee for their valuable comments. The second author gratefully acknowledges the financial support of Grants-in-Aid for Scientific Research (C) from the Japan Society for the Promotion of Science (15K03431). The usual disclaimer applies.

\section{Conflicts of Interest}

The authors declare no conflicts of interest regarding the publication of this paper.

\section{References}

[1] Greiner, A. (2013) Debt and Growth: Is There a Non-Monotonic Relation? Economics Bulletin, 33, 340-347.

[2] Reinhart, C.M. and Rogoff, K.S. (2010) Growth in a Time Debt. American Economic Review Papers and Proceedings, 100, 573-578. https://doi.org/10.1257/aer.100.2.573

[3] Checherita-Westphal, C. and Rother, P. (2010) The Impact of High and Growing Debt on Economic Growth. An Empirical Investigation for the Euro Area. ECB Working Paper Series 1237, European Central Bank.

[4] Reinhart, C.M., Reinhart, V.R. and Rogoff, K.S. (2012) Public Debt Overhangs: Advanced-Economy Episodes Since 1800. Journal of Economic Perspectives, 26, 69-86. https://doi.org/10.1257/jep.26.3.69

[5] Baum, A., Checherita-Westphal, C. and Rother, P. (2012) Debt and Growth New Evidence for the Euro Area. ECB Working Paper Series 1450, European Central Bank.

[6] Saint-Paul, J. (1992) Fiscal Policy in an Endogenous Growth Model. Quarterly Journal of Economics, 107, 1243-1259. https://doi.org/10.2307/2118387

[7] Blanchard, O. (1985) Debt, Deficit, and Finite Horizons. The Journal of Political Economy, 92, 223-247. https://doi.org/10.1086/261297 
[8] Bräuninger, M. (2005) The Budget Deficit, Public Debt and Endogenous Growth. Journal of Public Economic Theory, 7, 827-840. https://doi.org/10.1111/j.1467-9779.2005.00247.x

[9] Barro, R.J. (1990) Government Spending in a Simple Model of Endogenous Growth. Journal of Political Economy, 98, S103-S126. https://doi.org/10.1086/261726

[10] Futagami, K., Morita, Y. and Shibata, A. (1993) Dynamics Analysis of an Endogenous Growth Model with Public Capital. Scandinavian Journal of Economics, 95, 607-625. https://doi.org/10.2307/3440914

[11] Checherita-Westphal, C., Hallett, A.H. and Rother, P. (2014) Fiscal Sustainability Using Growth Maximizing Debt Targets. Applied Economics, 46, 638-647. https://doi.org/10.1080/00036846.2013.861590

[12] Ghosh, S. and Mourmouras, I.A. (2004) Debt, Growth and Budgetary Regimes. Bulletin of Economic Research, 56, 241-250. https://doi.org/10.1111/j.1467-8586.2004.00200.x

[13] Bokan, N., Hallett, A. and Hougaard Jensen, S. (2016) Growth-Maximizing Public Debt under Changing Demographics. Macroeconomic Dynamics, 20, 1640-1651. https://doi.org/10.1017/S1365100514000947

[14] Kamiguchi, A. and Tamai, T. (2019) Public Investment, Public Debt, and Population Aging under the Golden Rule of Public Finance. Journal of Macroeconomics, 60, 110-122. https://doi.org/10.1016/j.jmacro.2019.01.011

[15] Ueshina, M. (2018) The Effect of Public Debt on Growth and Welfare under the Golden Rule of Public Finance. Journal of Macroeconomics, 55, 1-11. https://doi.org/10.1016/j.jmacro.2017.08.004

[16] Huňady, J. and Orviská, M. (2015) The Non-Linear Effect of Corporate Taxes on Economic Growth. Timisoara Journal of Economics and Business, 8, 14-31. https://doi.org/10.1515/tjeb-2015-0002

[17] Minea, A. and Villieu, P. (2009) Borrowing to Finance Public Investment? The "Golden Rule of Public Finance" Reconsidered in an Endogenous Growth Setting. Fiscal Studies, 30, 103-113. https://doi.org/10.1111/j.1475-5890.2009.00091.x

[18] Groneck, M. (2010) A Golden Rule of Public Finance or a Fixed Deficit Regime? Economic Modelling, 2, 523-534. https://doi.org/10.1016/j.econmod.2009.11.005

[19] Aschauer, D.A. (1989) Is Public Expenditure Productive? Journal of Monetary Economics, 23, 177-200. https://doi.org/10.1016/0304-3932(89)90047-0 


\section{Appendix: A Condition for Non-Negative Long-Run Growth}

Equation (16) can be rewritten as

$$
(1-\psi) g^{*}=\left[\tau-(1-\tau)(1-\alpha) \psi z^{*}\right] A z^{* \alpha-1}
$$

Substitution for $z^{*}$ from Equation (11) into Equation (A.1) implies

$$
(1-\psi) g^{*}=\tau A\left[\frac{g^{*}+\rho}{(1-\tau)(1-\alpha) A}\right]^{\frac{1-\alpha}{\alpha}}-\psi\left(g^{*}+\rho\right) .
$$

After some manipulation, the above equation can be rewritten in the following form:

$$
\left(\mathrm{LHS}^{\prime}=\right) g^{*}+\psi \rho=\tau A\left[\frac{(1-\tau)(1-\alpha) A}{g^{*}+\rho}\right]^{\frac{1-\alpha}{\alpha}}\left(=\mathrm{RHS}^{\prime}\right)
$$

The LHS curve and the RHS curve are depicted in Figure A1, which shows a unique $g^{*}$.

As Figure A1 indicates an increases in $\psi$ reduces the long-run rate of growth ${ }^{9}$. Also, from Figure A2, the following condition can be derived under which the steady state growth rate is non-negative.

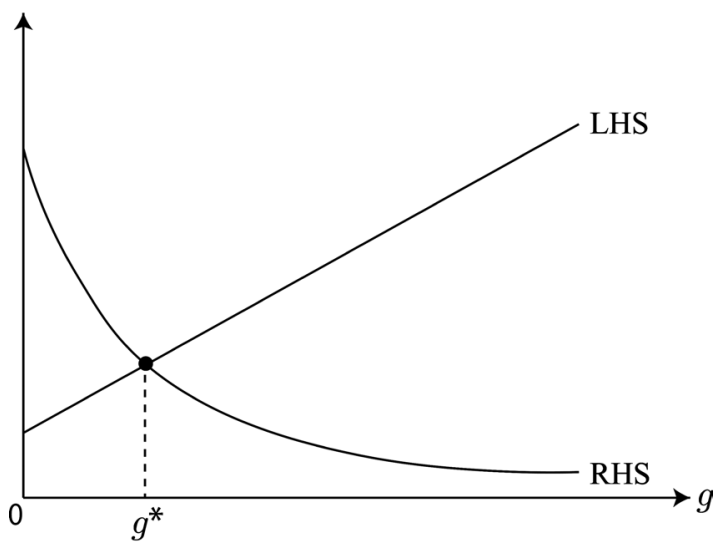

Figure A1. Existence of equilibria.

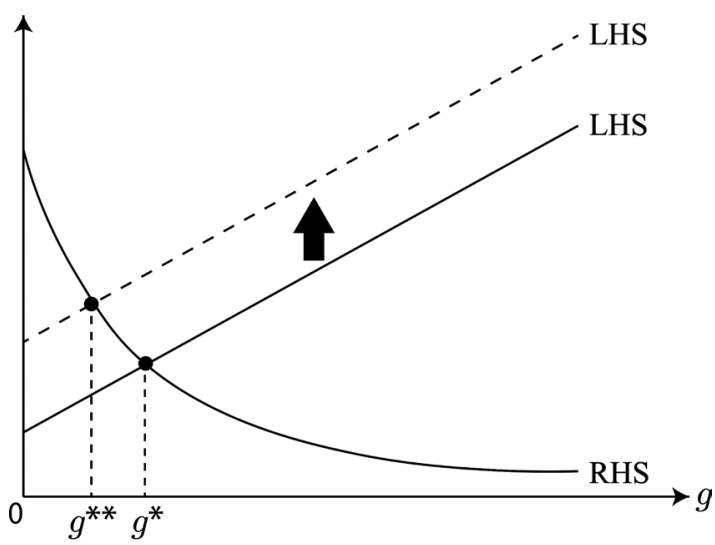

Figure A2. Effects of increase in $\psi$.

${ }^{9}$ Greiner [1] also shows the same comparative static result. 


$$
\tau A\left[\frac{(1-\tau)(1-\alpha) A}{g^{*}+\rho}\right]^{\frac{1-\alpha}{\alpha}} \geq \psi \rho .
$$

The above inequality can be rewritten as

$$
\psi \leq \tau[(1-\alpha)(1-\tau)]^{\frac{1-\alpha}{\alpha}}(A / \rho)^{\frac{1}{\alpha}}(=\bar{\psi}) .
$$

The long-run growth is negative if Inequality (A.3) is not met. In order to examine the plausibility, let us present the numerical example in which it is assumed that $\rho=0.05, A=0.15, \alpha=0.25^{10}$. As Table A1 shows, $\bar{\psi}$ is greater than one, i.e., Inequality (A.3) holds for a plausible range of $\tau$ $(0.05 \leq \tau \leq 0.7)$. Hence, it can be concluded that the long-run growth is positive.

Table A1. $\bar{\psi}$ and long-run growth rate.

\begin{tabular}{ccc}
\hline$\tau$ & $\bar{\psi}$ & $g^{*} \times 100$ \\
\hline 0.05 & 1.46 & $0.50 \%$ \\
0.1 & 2.49 & $1.28 \%$ \\
0.2 & 3.50 & $1.84 \%$ \\
$(0.25)$ & $(3.60)$ & $(1.89 \%)$ \\
0.3 & 3.52 & $1.85 \%$ \\
0.4 & 2.95 & $1.55 \%$ \\
0.5 & 2.14 & $1.04 \%$ \\
0.6 & 1.31 & $0.35 \%$ \\
0.7 & -0.65 & $-0.52 \%$ \\
\hline
\end{tabular}

Note: Numbers in parenthesis are those under maximum growth \& $\bar{\psi} \equiv \tau[(1-\alpha)(1-\tau)]^{(1-\alpha) / \alpha}(A / \rho)^{\frac{1}{\alpha}}$.

${ }^{10}$ The same parameter values are also adapted in Greiner [1]. A time preference rate of $\rho=0.05$ is commonly adopted in many studies. A public capital elasticity of $\alpha=0.25$ is also adopted in many studies (for example, Barro [9]. On the other hand, Minea and Villieu [17] and Groneck [18] choose $\alpha=0.4$ according to Aschauer [19]. 